\title{
Analysis of Average Crack Spacing of UHTCC Reinforced Beams
}

\author{
Huaqiang $\mathrm{Yu}^{1,}$, Mingqiang $\operatorname{Lin}^{1,}$ a \\ ${ }^{1}$ School of Civil Engineering and Architecture,University of Jinan, China \\ ahonfay@163.com
}

\begin{abstract}
Keywords: UHTCC,average crack spacing,reducing.
Abstract. UHTCC is a new type of material which is widely used in this study. It is effective to improve the performance of damaged reinforced concrete and improve its durability. UHTCC is applied to the reinforcement of concrete structure. There is no clear and effective method of calculating. How much of the UHTCC limit for cracks can be measured by the concept of average crack spacing.
\end{abstract}

\section{Introduction}

Into the 20th century, the concrete has gradually become the most important building materials, it has easy to draw, reasonable timber, good durability, good fire resistance, good moldability, good integrity, etc., only in China, there are about 20 billion cubic of concrete for a variety of projects. [1]However, there are many shortcomings of concrete, such as large weight, poor crack resistance, complex construction, poor insulation and other shortcomings. So that the use of concrete in the process even in the construction process will be such a problem, especially the existence of cracks. Cracks in concrete are used throughout the period, and its cracking is almost unavoidable. However, the existence of cracks to the concrete structure has brought a lot of problems for corrosive media intrusion of concrete provides a channel, how to control the cracks in concrete has become the existing technical conditions expedient.[2]

In the actual engineering, for the already appeared cracks in the reinforced concrete structure, often with reinforced concrete, paste plate, FRP material reinforcement and fiber reinforced cement composite materials and other methods to limit the development of cracks, play the role of reinforcement structure. The commonality of these methods is to increase a high tensile strength, good toughness of the material to control the development of cracks to reduce the width of the cracks, thereby reducing the cracking of concrete for the entire structure of the harm. Rigid reinforced concrete is a simple and direct reinforcement method, by spraying concrete method, in the original structure of the tensile part of a layer of concrete, while in the concrete coupled with the tensile reinforcement, in order to improve the resistance of the original structure and resistance Crack ability. Bonded steel reinforcement method is to improve the method of adding concrete layer, with steel instead of concrete, and with the characteristics of the building structure glue paste steel plate to improve the structure of the bending, shear, compression bearing capacity, enhanced structural resistance of a reinforcement method. This method has been widely used since the 1960s, and has been widely used in industrial and civil construction fields and in the field of roads and bridges. The shortcomings of this method from the nature of the steel itself is easy to corrosion, the overall installation, a large weight, easy to operate, the construction quality is difficult to guarantee.[3] FRP material reinforcement is a new type of concrete reinforcement method, which uses impregnated resin to the fiber cloth posted on the concrete surface, the use of fiber cloth good tensile properties and toughness, play a role in strengthening the concrete. [4]Compared with the first two methods, it has many advantages such as light weight, anti-corrosion, easy forming, simple construction and easy to guarantee the quality, and it is well applied in engineering. Of course, due to its coordination with the concrete material problems, prone to interfacial stress concentration and other issues. Fiber Reinforced Cement-based Composites (UHTCC) improve the toughness of the material by allowing the material to pass through a number of fine fractures during stretching. The obtained composite material has a 
tensile strain of $3 \%$ or more in the case of a fiber content of only $2 \%$ by volume, with better crack control, bending toughness and higher energy consumption, It is light weight, easy to corrosion, good durability, and concrete bonding and other advantages, is very suitable for repair and reinforcement of concrete.[5]

Therefore, this paper analyzes the crack prediction mechanism of reinforced concrete structure reinforced by fiber reinforced cement-based composite materials from the perspective of fracture mechanism and crack control measures, and is used to predict the effect of fiber reinforced cement-based composites reinforced concrete.

\section{The mechanism of concrete crack propagation}

When the cracks are not present, the tensile stress and the tensile strain of the concrete are different in the pure bending section of the bending member. At this time, the reinforcement of the steel bar and the concrete is good, the tensile stress and the tensile strain are basically the same one.[1]

When the concrete outside the draw zone reaches its tensile strength $\mathrm{ft} 0$, its tensile strain is close to the ultimate tensile strain of concrete, it is in the state of cracking. As the strain reaches the ultimate strain, the first cracks appear. After cracking of the concrete, the cracks at the cracks in the concrete played a role in the constraints of the cracks will not be infinite development.

\section{Reinforcement of concrete for cracks}

The cracking of the concrete at the crack is constrained by the corresponding position of the steel bar, mainly because of the strong bond stress between the reinforced concrete and the concrete. Through the stress of the bond, the tensile stress of the concrete increases from zero at the crack to reach a certain After the length, the bonding stress between the two disappears, and the stress of the concrete tends to be evenly distributed. Here, that is the length of the bond stress effect.

\section{Analysis of the Effect of Fiber Reinforced Cement - based Composites on Concrete Cracks}

The fiber-reinforced cement-based composite material is located on the outside of the tensioned side of the structural member and is bonded to the original member. The effect of the fiber reinforced cement-based composite material on the crack of the concrete structure is similar to that of the reinforcing bar. The stress of the joints and the fiber reinforced cement-based composites are constrained by the bond stress of the components. Therefore, the effect of the fiber-reinforced cement-based composite material on the fracture can be attributed to the role of the reinforcement, which can be analyzed by using the existing formula for the prediction and calculation of the crack width.

\section{Mean crack spacing correction}

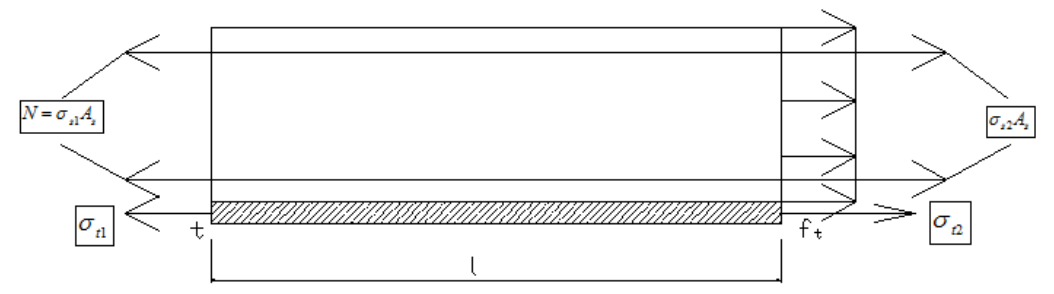

Fig. 1 


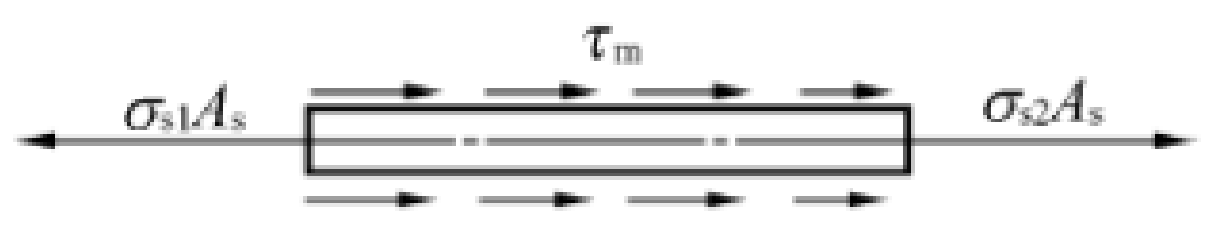

Fig. 2

As shown in Figure 1, when the weak cross-section cracks, the tensile stress of concrete will be zero, steel stress suddenly increased to $\sigma_{s 1}$, as mentioned above, through the transmission of adhesive stress, after the transfer length, the concrete tensile stress from zero The bond stress of UHTCC and concrete and the bond stress of reinforced concrete and concrete are $T_{m l}, T_{m 2}$, The ratio is $k$.

According to Figure 1, according to the balance of force, you can write the following formula $\sigma_{t 1} b t+\sigma_{s 1} A_{s}=\sigma_{s 2} A_{s}+f_{t} A_{t e}+\sigma_{t 2} b t$

$\sigma_{t 1} b t=\tau_{m 1} b l+\sigma_{t 2} b t$

According to Figure 2, according to the balance of force, you can write

$$
\sigma_{s 1} A_{s}=\sigma_{s 2} A_{s}+\tau_{m 2} u l
$$

(2) and (3) into the (1) type available

$\tau_{m 1} b l+\tau_{m 2} u l=f_{t} A_{t e}$

$\tau_{m 2}(k b+u) l=f_{t} A_{t e}$

$l=\frac{f_{t}}{\tau_{m 2}} \frac{A_{t e}}{k b+u}$

Compared with the basic formula of the average crack spacing when not being reinforced, it is found that the distance from the $u$ becomes $k b+u$, the spacing becomes smaller.

\section{Conclusions}

By applying the dimensionally reinforced cementitious composites, the average crack spacing of the beams is reduced due to the limitation of the material on the cracks of the concrete structures, thus 
forming the fractures with small and dense cracks, which greatly improves the durability of the structures.

\section{Acknowledgements}

This work was financially supported by the University of Jinan Science Foundation (XKY1520), Shandong Province Science and Technology Project of Higher Education(J15LG54) .

\section{References}

[1] Cheng Wenxiang. Concrete structure[M]. Beijing: China Architecture and Building Press,2012. (in Chinese) .

[2] Wang Tiemeng. Crack control for engineering structure[M]. Beijing: China Architecture and Building Press, 1997. (in Chinese).

[3] Zhou Xiang. Sticks the steel reinforcement law in the railroad frame bridge reinforcement application [J]. China Water Transport, 2007, 5(6): 71- 73. (in Chinese) .

[4] Zhang Dapeng. Behavior of concrete members strengthened with carbon fiber reinforced plastic sheets [D]. Dalian: Dalian University of Technology, 2006. (in Chinese) .

[5] Li Hedong, $\mathrm{Xu}$ Shilang. Experimental research on Ultra high toughness cementitious composites [D]. Dalian: Dalian University of Technology, 2008. (in Chinese). 